\title{
Transformable DNA Nanocarriers for Plasma Membrane Targeted Delivery of
}

\section{Cytokine}

Wujin Sun ${ }^{\mathrm{a}, \mathrm{b}}$, Wenyan Ji ${ }^{\mathrm{a}, \mathrm{b}}$, Quanyin $\mathrm{Hu}^{\mathrm{a}, \mathrm{b}}$, Jicheng $\mathrm{Yu}^{\mathrm{a}, \mathrm{b}}$, Chao Wang ${ }^{\mathrm{a}, \mathrm{b}}$, Chenggen Qian ${ }^{\mathrm{a}, \mathrm{b}}$, Gabrielle Hochu ${ }^{\mathrm{a}}$, Zhen $\mathrm{Gu}^{\mathrm{a}, \mathrm{b}, \mathrm{c}, *}$

${ }^{a}$ Joint Department of Biomedical Engineering, University of North Carolina at Chapel Hill and North Carolina State University, Raleigh, NC 27695, USA.

${ }^{b}$ Division of Molecular Pharmaceutics and Center for Nanotechnology in Drug Delivery, Eshelman School of Pharmacy, University of North Carolina at Chapel Hill, Chapel Hill, NC 27599, USA

${ }^{c}$ Department of Medicine, University of North Carolina School of Medicine, Chapel Hill, NC 27599, USA

*Corresponding author. E-mail address: zgu@email.unc.edu (Z.Gu) 


\begin{abstract}
Direct delivery of cytokines using nanocarriers holds great promise for cancer therapy. However, the nanometric scale of the vehicles made them susceptible to size-dependent endocytosis, reducing the plasma membrane-associated apoptosis signalling. Herein, we report a tumor microenvironment-responsive and transformable nanocarrier for cell membrane targeted delivery of cytokine. This formulation is comprised of a phospholipase A2 (PLA2) degradable liposome as a shell, and complementary DNA nanostructures (designated as nanoclews) decorated with cytokines as the cores. Utilizing the tumor necrosis factor-related apoptosis-inducing ligand (TRAIL) as a model cytokine, we demonstrate that the TRAIL loaded DNA nanoclews are capable of transforming into nanofibers after PLA2 activation. The nanofibers with micro-scaled lengths efficiently present the loaded TRAIL to death receptors on the cancer cell membrane and amplified the apoptotic signalling with reduced TRAIL internalization.
\end{abstract}

Key words: cancer, protein delivery, DNA structures, DNA, cytokine, nanomedicine 


\section{Introduction}

Delivering protein based anticancer therapeutics[1-4], such as enzymes [5-7], transcription factors [8-10], or cytokines [11-13], are gaining increasing interest due to their specific activities in inducing apoptosis in cancer cells, reducing normal cell damage than traditional chemotherapeutics $[14,15]$. When compared with delivering nucleic acid based anticancer gene therapies, directly administering protein formulations would enable better control of the dosages as well as ruling out the chance of accidental genetic alterations [16]. While reaching intracellular compartments is a prerequisite for many anticancer proteins, like the caspase- 3 that transmits apoptosis signal in the cytosol [17], or apoptin that takes effect in the nucleus [18]; blocking the endocytosis of proteins that target specific receptors on the plasma membrane would enhance their signaling, such as the tumor necrosis factor-related apoptosis-inducing ligand (TRAIL), a cytokine that interacts with death receptors on the plasma membrane and induces tumor specific apoptosis [19, 20]. However, current anticancer protein delivery systems were mostly designed for intracellular delivery by harnessing the size-dependent endocytosis of nanoparticles [21-23]; strategies for targeted delivery of nanocarriers to plasma membranes while avoiding size-dependent endocytosis remain elusive.

Here, we describe a novel rolling circle amplification (RCA) based strategy for cancer cell membrane targeted delivery of cytokine in a tumor-microenvironment responsive manner [20, 24-26], where the secreted phospholipase A2 (PLA2), an enzyme overexpressed by various tumors, including colon, breast, prostate, and gastric cancers [27], was harnessed as a 
spatial-temporal trigger for drug release. Compared with conventional DNA structure preparation techniques that require sophisticated DNA oligo design and assembly [28-33], rolling circle amplification (RCA) is a facile DNA synthesis technique capable of preparing DNA structures spanning the spatial range from nano- [34-38] to micro- $[39,40]$ and to macroscopic scale [41-43]. One amazing property of DNA is that folded DNA nanostructures are readily internalized by many types of cancer cell lines [44-47], while free DNA chains are impermeable to cell membranes [48]. In our previous reports, we prepared self-assembled DNA nanoclews (NCs) by RCA for nuclei targeted delivery of Doxorubicin as a tumor microenvironment-triggered anticancer therapy [34] or the CRISPR-Cas9 system for targeted genome editing [16]. However, these compact nanocarriers were tailored for intracellular targets. To achieve plasma membrane-targeted cytokine delivery, as shown in Fig. 1, nanoparticles with a core-shell structure were designed consisting of two functional components: 1) a liposome shell that could be specifically degraded by PLA2 and 2) two DNA NCs encoding complementary sequences as the cores. For convenient designation, one of the complementary DNA NCs was defined as encoding DNA sequence in the forward direction ( $\mathrm{NCf}$ ), while the other was defined as encoding sequence in the reverse direction ( $\mathrm{NCr}$ ). The model cytokine TRAIL was loaded onto the $\mathrm{Ni}^{2+}$ modified DNA NC cores via $\mathrm{Ni}^{2+}$-polyhistidine affinity. We hypothesized that the elevated PLA2 level in the tumor microenvironment would promote degradation of the liposome shell, releasing the TRAIL loaded DNA NCs into extracellular environment. In cases when only one of TRAIL-NCf-L or TRAIL-NCr-L was administered, rapid internalization of the TRAIL 
loaded DNA NC would happen, diminishing the apoptosis signaling induction. However, when both TRAIL-NCf-L and TRAIL-NCr-L were co-administered, hybridization of the complementary DNA NCs could occur extracellularly, transforming the compact DNA nanoparticles into micro-scaled DNA structures that could serve as multivalent scaffolds for presenting TRAIL to death receptors on plasma membrane and reduce its endocytosis to enhance the anticancer efficacy.

\section{Materials and Methods}

\subsection{Materials}

All chemicals unless otherwise specified were purchased from Sigma-Aldrich and were used as received. DNA oligos were ordered from Integrated DNA Technologies Inc. (Coralville, IA, USA). Bst 2.0 DNA polymerase was purchased from New England BioLabs Inc. (Ipswich, MA, USA). CircLigase II single-stranded DNA (ssDNA) Ligase was purchased from Epicenter (Madison, WI, USA). Aminoallyl-dUTP and Traut's reagent were purchased from ThermoFihser Scientific, Inc. (Pittsburgh, PA, USA). Maleimido-C3-NTA was purchased from Dojindo Molecular Technologies Inc. (Kumamoto, Japan).

\subsection{Preparation of TRAIL}

Recombinant TRAIL was expressed and purified as described previously [49]. Briefly, Escherichia coli harboring the plasmid pET23dw-His-ILZ-hTRAIL that encodes His-ILZ-TRAIL (residues 114-281) was cultured in LB medium until the $\mathrm{OD}_{600}$ reached 0.6-0.8. $0.5 \mathrm{mM}$ 
isopropylthio- $\beta$-galactoside (IPTG) was added to induce TRAIL expression at $20^{\circ} \mathrm{C}$ for $12 \mathrm{~h}$. The cells were then collected by centrifugation and resuspended in buffer $\mathrm{A}(20 \mathrm{mM}$ Tris- $\mathrm{HCl}, \mathrm{pH} 8.0$, $20 \mathrm{mM}$ imidazole). After lysis by sonication and centrifugation at $20,000 \times \mathrm{g}$ for $20 \mathrm{~min}$, the supernatant of cell lysate was applied to a column containing NTA-Ni ${ }^{2+}$ resin. Followed by washing the column with buffer B (20 mM Tris- $\mathrm{HCl}, \mathrm{pH} 8.0,60 \mathrm{mM}$ imidazole), TRAIL was eluted by buffer $\mathrm{C}(20 \mathrm{mM}$ Tris- $\mathrm{HCl}, \mathrm{pH} 8.0,500 \mathrm{mM}$ imidazole) and dialyzed against PBS at $4{ }^{\circ} \mathrm{C}$ overnight. The purified TRAIL was quantified by Bradford assay and analyzed by SDS-PAGE.

\subsection{Preparation of $\mathrm{Ni}^{2+}$ modified DNA NC}

Two complementary DNA NCs modified with $\mathrm{NH}_{2}$ were prepared by RCA [34] with further modifications to obtain $\mathrm{Ni}^{2+}$ modified DNA NCs. The ssDNA templates with 5' phosphorylation (Table 1) were cyclized by CircLigase II following manufacturer's instructions and uncyclized ssDNA chains were removed with Exonuclease I (NEB). NCs modified with primary amines were then prepared by applying aminoallyl-dUTP as a building block in the RCA reaction. Briefly, 10 pmol circular ssDNA templates were hybridized with corresponding primers at $95{ }^{\circ} \mathrm{C}$ for $5 \mathrm{~min}$ in $1 \times$ isothermal amplification buffer (NEB) supplemented with $200 \mu \mathrm{M}$ dUTP and 2 $\mu \mathrm{M}$ aminoallyl-dUTP. After cooling the solution to room temperature, Bst 2.0 DNA polymerase $(0.2 \mathrm{U} / \mu \mathrm{L})$ was added and the reaction was kept at $60{ }^{\circ} \mathrm{C}$ for $17 \mathrm{~h}$. The synthesized NCs were centrifuged at $14,000 \times \mathrm{g}$ for $2 \mathrm{~min}$ and dialyzed against buffer $\mathrm{D}(10 \mathrm{mM}$ phosphate buffer, $\mathrm{pH}$

7.4, $2.5 \mathrm{mM}$ EDTA) in a Slide-A-Lyzer dialysis unit (20K MWCO, Thermo Scientific). The 
primary amines on NCs were then conjugated with thiol groups using $5 \mu \mathrm{M}$ Traut's reagent at room temperature for $1 \mathrm{~h}$ and the thiolation was confirmed by thiol detection kit (Cayman) with an efficiency over 95\%. $20 \mu \mathrm{M}$ maleimido-C3-NTA was then added to conjugate NTA to the thiol groups at room temperature for 3 h.[50] After chelating the NTA with $50 \mu \mathrm{M} \mathrm{NiCl}$, the $\mathrm{Ni}^{2+}$ modified DNA NCs were dialyzed against deionized water for 2-3 days. Concentrations of the prepared DNA NCs were determined using Nanodrop 2000C spectrometer (Thermo Scientific). Zeta potential and particle size were analyzed by Zetasizer (Nano ZS, Malvern). Transmission electron microscopy (TEM) images of the NCs were acquired on a JEOL 2000FX microscope at $200 \mathrm{kV}$ with the samples prepared on a TEM copper grid (300 mesh) (Ted Pella) and stained by phosphotungstic acid (1\%, v:v). Elemental mapping of the DNA NCs were performed on an FEI Titan 80-300 aberration corrected STEM with SuperX energy dispersive X-ray spectroscopy (EDS) system.

\subsection{Characterization of DNA NCs loaded with TRAIL}

The His-tagged TRAIL protein was loaded onto $\mathrm{Ni}^{2+}$ modified DNA NCs $(1: 40, \mathrm{w}: \mathrm{w})$ via the affinity between the His-tag and $\mathrm{Ni}^{2+}$ with an excess of $\mathrm{Ni}^{2+}$. The TRAIL loaded NCs, TRAIL-NCf and TRAIL-NCr, were then visualized by confocal laser scanning microscope (CLSM) with TRAIL labeled by Alexa Fluor 647 (AF 647) and NCs stained with Hoechst 33342. To obtain TEM image of TRAIL loaded DNA NC, TRAIL was pre-stained with mono-sulfo- $N$-hydroxy-succinimido gold nanoparticle in PBS for $1 \mathrm{~h}$ and excessive gold nanoparticle (AuNP) was removed by Seperdex-75 gel filtration. Silver enhancement was applied 
for better TEM imaging. For atomic force microscope (AFM) imaging, the $\mathrm{NCf}$ and $\mathrm{NCr}$ were dropped, dried on the silicon wafer and imaged by tapping mode in ambient air using a Nanoscope AFM (Veeco, Santa Barbara, CA). Particle size and zeta potential of TRAIL loaded NCs were characterized by Zetasizer (Nano ZS, Malvern).

\subsection{Encapsulation of DNA NC into liposome and PLA2 triggered release}

The TRAIL loaded DNA NCs were encapsulated into 1-palmitoyl-2-oleoyl-sn-glycero-3-phosphocholine (POPC) liposome by reverse phase evaporation. Briefly, POPC dissolved in chloroform $(1 \mathrm{mg} / \mathrm{mL})$ and water solution containing TRAIL-NC were mixed (3:1, v:v). A nano-emulsion was obtained after sonication and the emulsion was shortly evaporated by a rotary vacuum evaporator (Heidolph). Supplemented with another 1 volume of deionized water, the emulsion was evaporated again to remove excess chloroform from the solution. Unencapsulated TRAIL-NC was removed by dialysis against deionized water in a $1000 \mathrm{KDa}$ dialysis unit (Spectrum) after DNase treatment. Particle size and zeta potential of liposome were characterized by Zetasizer (Nano ZS, Malvern). POPC liposome was lysed with Triton X-100 aqueous solution (1\%, v:v) for rapid release of its content. For phospholipase mediated release, $15 \mathrm{U} / \mathrm{mL}$ of PLA2 from Naja mossambica mossambica (Sigma Aldrich) was incubated with the liposome at room temperature for $10 \mathrm{~min}[51,52]$. The release of TRAIL-NC from the POPC liposome was analyzed by $0.8 \%$ agarose gel electrophoresis with GelRed supplemented as DNA stain and band fluorescence intensity was estimated with Image J. The POPC liposome were also characterized by TEM imaging. 


\subsection{Cell culture}

The human colorectal cancer cell line COLO 205 was cultured in Dulbecco's Modified Eagle's Medium (DMEM) supplemented with $10 \%$ FBS (v:v), $100 \mathrm{U} / \mathrm{mL}$ penicillin and 100 $\mu \mathrm{g} / \mathrm{mL}$ streptomycin in a $37{ }^{\circ} \mathrm{C}$ incubator (Thermal Scientific) under an atmosphere of $5 \% \mathrm{CO}_{2}$ and $90 \%$ humidity. The cells were sub-cultured regularly with a split ratio of 1:3 and the cell densities were quantified using a hemocytometer before each experiment.

\subsection{Cellular distribution and endocytosis pathway of delivered TRAIL}

Subcellular localization of delivered TRAIL was monitored using CLSM. COLO 205 cells were seeded in confocal microscopy dishes (MatTek) at the density of $1 \times 10^{5}$ cells/well and cultured for $48 \mathrm{~h}$. The cells were then incubated with different formulations containing $50 \mathrm{ng} / \mathrm{mL}$ of AF 647 labeled TRAIL at $37{ }^{\circ} \mathrm{C}$ for $1 \mathrm{~h}$. After washing the cells with ice-cold PBS twice, the cell membranes were stained with $5 \mu \mathrm{g} / \mathrm{mL}$ Alexa Fluor 488 conjugated Wheat Germ Agglutinin (WGA) at $37^{\circ} \mathrm{C}$ for 10 min. The stained cells were then washed with ice-cold PBS again and observed with CLSM immediately. For quantitative analysis of membrane-bound TRAIL, COLO 205 cells were seeded in 6 -well plates $\left(1 \times 10^{5}\right.$ cells $/$ well $)$ and cultured for $48 \mathrm{~h}$. The cells were treated with different formulations containing $50 \mathrm{ng} / \mathrm{mL}$ of AF 647 labeled TRAIL for $1 \mathrm{~h}$ at $37^{\circ} \mathrm{C}$ or $4{ }^{\circ} \mathrm{C}$. Afterwards, the cells were collected and analyzed by flow cytometry (Cytoflex, Beckman Coulter) to quantify the total TRAIL contents of the cells, including membrane bound and internalized, by measuring the mean fluorescence intensities of the cells. Samples treated at $37^{\circ} \mathrm{C}$ represent the total amount the both membrane-bound and internalized TRAIL while the 
those treated at $4{ }^{\circ} \mathrm{C}$ were referred only as TRAIL bound to the cell membrane due the inhibition of endocytosis at $4{ }^{\circ} \mathrm{C}$ [49]. The uptake pathway of delivered TRAIL (stained with AF 647) was also analyzed. COLO 205 cells in the 6-well plates were pre-incubated with different inhibitors for endocytosis pathways for $1 \mathrm{~h}$ at $37{ }^{\circ} \mathrm{C}$ [chlorpromazine $(\mathrm{CPZ}, 10 \mu \mathrm{M})$ for clathrin-mediated endocytosis; methyl- $\beta$-cyclodextrin (MCD, $3 \mathrm{mM}$ ) for lipid raft; nystatin (NYS, $25 \mu \mathrm{g} / \mathrm{mL}$ ) for cavelolin-mediated endocytosis; and amiloride (AMI, $1 \mathrm{mM}$ ) for macropinocytosis]. Then the cells were incubated with PLA2 pretreated TRAIL-NCf-L or TRAIL-NCr-L in the presence of the inhibitors for another $2 \mathrm{~h}$. Mean fluorescence intensities of the cells were analyzed by flow cytometry.

\subsection{Cell apoptosis assay}

The apoptosis inducing capability of TRAIL delivered by different formulations were evaluated with the APO-BrdU based terminal deoxynucleotidyl transferase (TdT) dUTP Nick-End Labeling (TUNEL) assay kit (Life Technologies) and the Annexin V-FITC Apoptosis Detection Kit (BD Bioscences). COLO 205 cells were seeded in 6-well plates and cultured for 48 h. The cells were incubated with different formulations containing $20 \mathrm{ng} / \mathrm{mL}$ of TRAIL for $12 \mathrm{~h}$. Afterwards, the cells were stained following the protocol of the manufacturers. For the TUNEL assay, the cells were imaged by fluorescence microscope (IX71, Olympus), while for the Annexin V-FITC Apoptosis assay, the cells were analyzed by flow cytometry (Cytoflex, Beckman Coulter).

2.9. In vitro cytotoxicity 
COLO 205 cells were seeded in 96 well plates at the density of $1 \times 10^{4}$ cells/well and cultured for $24 \mathrm{~h}$. To evaluate the anticancer efficacy of TRAIL delivered by the NCs, the cells were incubated with TRAIL containing formulations at different TRAIL concentrations for $24 \mathrm{~h}$. To evaluate the biocompatibility of the carrier, nanocarriers without TRAIL were incubated with the cells at the same concentrations used for TRAIL delivery for $24 \mathrm{~h}$. MTT solutions were then added to the cells (final concentration of $0.5 \mathrm{mg} / \mathrm{mL}$ ) and incubated for $4 \mathrm{~h}$. After removing the medium, the cells were dissolved with $150 \mu \mathrm{L}$ DMSO and the absorbances were read on a microplate reader (Infinite M2000 Pro, Tecan) with test wavelength of $570 \mathrm{~nm}$ and reference wavelength of $630 \mathrm{~nm}$.

\subsection{Statistics}

All results were calculated as Mean $\pm \mathrm{SD}$. Two-tailed student's t-test was performed for statistical analysis. The difference between experimental groups and control groups were considered statistically significant when $P<0.05$ or highly significant when $P<0.01$.

\section{Results and Discussion}

\subsection{Preparation and characterization of $\mathrm{Ni}^{2+}$ modified DNA NC}

To validate our delivery strategy, we first synthesized the $\mathrm{NH}_{2}$-modified DNA NCs by RCA (Fig. 1a). Two ssDNA oligos with complementary sequences were used as templates for the RCA (Table 1). Aminoallyl-dUTP was supplemented into the RCA reaction for incorporating $\mathrm{NH}_{2}$ groups into the RCA products. After converting $\mathrm{NH}_{2}$ into $\mathrm{SH}$ with the Traut's reagent, maleimide 
activated nitrilotriacetic acid (NTA) was conjugated to the DNA NC for chelating $\mathrm{Ni}^{2+}$. Both $\mathrm{NCf}$ and $\mathrm{NCr}$ self-assembled into negatively charged nanoparticles (zeta potential of $-21 \pm 3 \mathrm{mV}$ ) with the mean size of $97 \mathrm{~nm}$ as determined by the TEM, AFM and dynamic light scattering (DLS) (Fig. 2a-c). The $\mathrm{Ni}^{2+}$ modification on DNA NC was confirmed by elemental analysis using the EDS mapping on a scanning transmission electron microscope (STEM) (Fig. 2d). Next, the morphology of the hybridized $\mathrm{NCf} / \mathrm{NCr}$ was evaluated by TEM and AFM. After incubating at $37^{\circ} \mathrm{C}$ for $10 \mathrm{~min}$, the fully complementary NCf and NCr merged into micro-scaled fibers (Fig. 2b and c). Due to the periodic nature of the DNA strands, strong hybridization of multiple DNA stands generated networked fibers with a width of $\sim 40 \mathrm{~nm}$ and length spanning a few micrometers.

\subsection{Loading TRAIL onto DNA NC}

TRAIL with a molecular weight of $24 \mathrm{KDa}$ was purified (Fig. 3a) and loaded onto the synthesized DNA NCs via the affinity between $\mathrm{Ni}^{2+}$ and the fused His-tag on TRAIL. To image the loading of TRAIL onto DNA NC by TEM, TRAIL was labeled with gold nanoparticle. Both NCf and NCr were efficient in loading the His-tagged TRAIL, which caused negligible changes to the zeta potential $(-20 \pm 4 \mathrm{mV})$ and sizes as compared with DNA NCs (Fig. 3b). Binding of the TRAIL protein to DNA NCs was also observed by CLSM with TRAIL labeled by the infrared AF 647 and NCs stained with Hoechst 33342 (Fig. 3c). Colocalization of the fluorescence signals further confirmed the binding between TRAIL and DNA NCs.

\subsection{Encapsulation of TRAIL-NC in POPC liposome and PLA2 triggered release}


To prevent the TRAIL loaded DNA NCs from premature hybridization, TRAIL-NCf and TRAIL-NCr were encapsulated in liposomes composed of POPC, separately, by the method of reverse evaporation [53]. The sn-2 acyl ester bond in POPC can be rapidly degraded by the surface active enzyme PLA2 [54], making POPC liposome a PLA2-responsive coating for TRAIL delivery. The POPC liposome containing TRAIL-NC showed a mean hydrodynamic size of $215 \mathrm{~nm}(\mathrm{PDI}=0.29 \pm 0.03$, zeta potential $-25 \pm 4 \mathrm{mV})($ Fig. $4 \mathrm{a})$ and the TRAIL-NC was encapsulated with an encapsulation efficiency of $55 \%$ (Fig. 4b). Treating the TRAIL-NC-L with PLA2 for 10 min triggered virtually complete release of the encapsulated TRAIL-NC from the liposome (Fig. 4c). When TRAIL-NC-L was treated with PLA2, the liposome structure was disrupted and nanoparticles with a size of $\sim 100 \mathrm{~nm}$ were released (Fig. 4d and e). However, microscaled fibers of hybridized TRAIL-NCf/TRAIL-NCr (1:1 w:w) were observed after PLA2 treatment of the TRAIL-NCf-L/TRAIL-NCr-L mix (Fig. 4f), reducing the portion of free nanoparticles.

\subsection{Cell membrane targeted delivery of TRAIL}

To evaluate the membrane targeted delivery of TRAIL by TRAIL-NCf-L/TRAIL-NCr-L, the human colorectal carcinoma cell COLO 205 was chosen as a model cell line due to the significantly elevated expression of PLA2 in its tumor extracellular matrix [55]. To compensate for the inadequate PLA2 secretion caused by the low cell density in the culture, PLA2 pretreatment was applied to release TRAIL-NC from the liposome. Subcellular localization of the delivered TRAIL was studied by incubating COLO 205 cells with TRAIL-NCf-L or 
TRAIL-NCr-L separately or simultaneously after PLA2 pretreatment of the liposome to mimic the tumor microenvironment. After incubation at $37^{\circ} \mathrm{C}$ for $1 \mathrm{~h}$, subcellular localization of AF 647 labeled TRAIL was observed by CLSM. As shown in Fig. 5a, TRAIL delivered by TRAIL-NCf-L or TRAIL-NCr-L separately was mostly internalized into the cells. However, the internalization was significantly inhibited when TRAIL-NCf-L and TRAIL-NCr-L were co-administered, leaving large part of the administered TRAIL bound on cell membrane. Quantitative analysis also confirmed that co-administration of two nanoparticles significantly enhanced the percentage of membrane-bound TRAIL to $\sim 76 \%$ from $\sim 42 \%$ by separately administered systems (Fig. $5 b$ ). Further analysis of the endocytosis pathways showed that the TRAIL delivered by TRAIL-NCf-L or TRAIL-NCr-L separately was mostly internalized into the COLO 205 cells through clathrin and lipid raft mediated pathways (Fig. 5c).

\subsection{In vitro cytotoxicity}

After confirming the membrane-targeted delivery of TRAIL by TRAIL-NCf-L/TRAIL-NCr-L, the enhanced apoptosis inducing capability of the co-administrated formulation was then evaluated by the TUNEL assay. Cells treated with TRAIL-NCf-L/TRAIL-NCr-L mixture after PLA2 pretreatment exhibited higher level of the apoptotic DNA fragmentation as observed from the green fluorescence signals compared with those incubated with separated formulations (Fig. 6a). The quantitative analysis of the apoptosis was performed using the Annexin-FITC staining based flow cytometry. As shown in Fig. 6b, the apoptosis ratios were $31.7 \%$ and $29.6 \%$ for PLA2 pretreated TRAIL-NCf-L and TRAIL-NCr-L, 
respectively; while after PLA2 pretreatment, TRAIL-NCf-L/TRAIL-NCr-L co-administration exhibited the highest apoptosis inducing capability with an apoptosis ratio of $43.7 \%$ after $12 \mathrm{~h}$ of incubation. The enhanced apoptosis of the co-delivered formulation is consistent with the increasing ratio of the membrane bound TRAIL.

The absence of PLA2 pretreatment basically abolished apoptosis inducing capability even for the co-administered formulation, indicating that the tumor microenvironment associated PLA2 is a required stimulus for TRAIL release. It is worth noting that, TRAIL bound to the NCs showed higher apoptotic signaling than free TRAIL, possibly due to the nanovectorization enhanced regional clustering of TRAIL [56]. The in vitro cytotoxicity of TRAIL against COLO 205 cells was examined by the 3-(4,5-dimethylthiazol-2-yl)-2,5-diphenyltetrazolium bromide (MTT) assay. Separately administered TRAIL-NCf-L and TRAIL-NCr-L after PLA2 pretreatment showed similar cytotoxicity with a half-maximal inhibitory concentration $\left(\mathrm{IC}_{50}\right)$ of $14 \mathrm{ng} / \mathrm{mL}$, which is significantly lower than that of TRAIL-L ( $\mathrm{IC}_{50}=24.2 \mathrm{ng} / \mathrm{mL}$ ) (Fig. 6c). TRAIL delivered by TRAIL-NCf-L and TRAIL-NCr-L simultaneously after PLA2 pretreatment showed further enhanced cytotoxicity towards COLO 205 cells $\left(\mathrm{IC}_{50}=7.8 \mathrm{ng} / \mathrm{mL}\right)$. Meanwhile, the empty vectors without loaded TRAIL did not show any significant cytotoxicity after PLA2 pretreatment (Fig. 6d), indicating the biocompatibility of the carriers.

\section{Conclusion}

In conclusion, we have exploited a novel cancer cell membrane targeted drug delivery 
system using two complementary DNA NCs as a drug loading matrix for regulating protein internalization. An enzyme degradable liposome was utilized for spatial-temporal hybridization of the DNA NCs. Of note, the morphological transformation of the nanoparticles $[20,57]$ into micro-scaled DNA structures effectively inhibited the endocytosis of TRAIL presenting nanoparticle into cancer cells, increasing its anticancer efficacy. This strategy provides new guidelines for design of cell membrane targeted drug delivery, which can be further expanded to other types of therapeutics.

\section{Acknowledgements}

This work was supported by the grants from NC TraCS, NIH's Clinical and Translational Science Awards (CTSA, NIH grant 1UL1TR001111) at UNC-CH. We acknowledge the use of the Analytical Instrumentation Facility (AIF) at NC State, which is supported by the State of North Carolina and NSF.

\section{References}

[1] Sun W, Lu Y, Gu Z. Advances in Anticancer Protein Delivery using Micro-/Nanoparticles. Part Part Syst Charact 2014;31:1204-22.

[2] Lu Y, Sun W, Gu Z. Stimuli-responsive nanomaterials for therapeutic protein delivery. J Control Release 2014;194:1-19.

[3] Gu Z, Biswas A, Zhao M, Tang Y. Tailoring nanocarriers for intracellular protein delivery. 
Chem Soc Rev 2011;40:3638-55.

[4] Ghosh P, Han G, De M, Kim CK, Rotello VM. Gold nanoparticles in delivery applications. Adv Drug Del Rev 2008;60:1307-15.

[5] Biswas A, Joo K-I, Liu J, Zhao M, Fan G, Wang P, et al. Endoprotease-Mediated Intracellular Protein Delivery Using Nanocapsules. ACS Nano 2011;5:1385-94.

[6] Tang R, Kim CS, Solfiell DJ, Rana S, Mout R, Velázquez-Delgado EM, et al. Direct Delivery of Functional Proteins and Enzymes to the Cytosol Using Nanoparticle-Stabilized Nanocapsules. ACS Nano 2013;7:6667-73.

[7] Anraku Y, Kishimura A, Kamiya M, Tanaka S, Nomoto T, Toh K, et al. Systemically Injectable Enzyme-Loaded Polyion Complex Vesicles as In Vivo Nanoreactors Functioning in Tumors. Angew Chem Int Ed 2016;128:570-5.

[8] Zhao M, Liu Y, Hsieh RS, Wang N, Tai W, Joo K-I, et al. Clickable Protein Nanocapsules for Targeted Delivery of Recombinant p53 Protein. J Am Chem Soc 2014;136:15319-25.

[9] Vegran F, Berger H, Boidot R, Mignot G, Bruchard M, Dosset M, et al. The transcription factor IRF1 dictates the IL-21-dependent anticancer functions of TH9 cells. Nat Immunol 2014;15:758-66.

[10] Liu Y, Du J, Choi J-s, Chen K-J, Hou S, Yan M, et al. A High-Throughput Platform for Formulating and Screening Multifunctional Nanoparticles Capable of Simultaneous Delivery of Genes and Transcription Factors. Angew Chem Int Ed 2015;128:177-81.

[11] Zitvogel L, Galluzzi L, Kepp O, Smyth MJ, Kroemer G. Type I interferons in anticancer 
immunity. Nat Rev Immunol 2015;15:405-14.

[12] Li J, Ai Y, Wang L, Bu P, Sharkey CC, Wu Q, et al. Targeted drug delivery to circulating tumor cells via platelet membrane-functionalized particles. Biomaterials 2016;76:52-65.

[13] Spiller KL, Nassiri S, Witherel CE, Anfang RR, Ng J, Nakazawa KR, et al. Sequential delivery of immunomodulatory cytokines to facilitate the M1-to-M2 transition of macrophages and enhance vascularization of bone scaffolds. Biomaterials 2015;37:194-207.

[14] Mitragotri S, Anderson DG, Chen X, Chow EK, Ho D, Kabanov AV, et al. Accelerating the Translation of Nanomaterials in Biomedicine. ACS Nano 2015;9:6644-54.

[15] Chow EK-H, Ho D. Cancer Nanomedicine: From Drug Delivery to Imaging. Sci Transl Med 2013;5:216rv4.

[16] Sun W, Ji W, Hall JM, Hu Q, Wang C, Beisel CL, et al. Self-Assembled DNA Nanoclews for the Efficient Delivery of CRISPR-Cas9 for Genome Editing. Angew Chem Int Ed 2015;54:12029-33.

[17] Gu Z, Yan M, Hu B, Joo K-I, Biswas A, Huang Y, et al. Protein Nanocapsule Weaved with Enzymatically Degradable Polymeric Network. Nano Lett 2009;9:4533-8.

[18] Zhao M, Hu B, Gu Z, Joo K-I, Wang P, Tang Y. Degradable polymeric nanocapsule for efficient intracellular delivery of a high molecular weight tumor-selective protein complex. Nano Today 2013;8:11-20.

[19] Kohlhaas SL, Craxton A, Sun XM, Pinkoski MJ, Cohen GM. Receptor-mediated endocytosis is not required for tumor necrosis factor-related apoptosis-inducing ligand 
(TRAIL)-induced apoptosis. J Biol Chem 2007;282:12831-41.

[20] Hu Q, Sun W, Lu Y, Bomba HN, Ye Y, Jiang T, et al. Tumor Microenvironment-Mediated Construction and Deconstruction of Extracellular Drug-Delivery Depots. Nano Lett 2016;16:1118-26.

[21] Gratton SEA, Ropp PA, Pohlhaus PD, Luft JC, Madden VJ, Napier ME, et al. The effect of particle design on cellular internalization pathways. Proc Natl Acad Sci USA 2008;105:11613-8.

[22] Gao H, Shi W, Freund LB. Mechanics of receptor-mediated endocytosis. Proc Natl Acad Sci USA 2005;102:9469-74.

[23] Tang L, Yang X, Yin Q, Cai K, Wang H, Chaudhury I, et al. Investigating the optimal size of anticancer nanomedicine. Proc Natl Acad Sci USA 2014;111:15344-9.

[24] Mo R, Gu Z. Tumor microenvironment and intracellular signal-activated nanomaterials for anticancer drug delivery. Mater Today 2015;doi:10.1016/j.mattod.2015.11.025.

[25] Wang H, Agarwal P, Zhao S, Xu RX, Yu J, Lu X, et al. Hyaluronic acid-decorated dual responsive nanoparticles of Pluronic F127, PLGA, and chitosan for targeted co-delivery of doxorubicin and irinotecan to eliminate cancer stem-like cells. Biomaterials 2015;72:74-89.

[26] Zhong J, Li L, Zhu X, Guan S, Yang Q, Zhou Z, et al. A smart polymeric platform for multistage nucleus-targeted anticancer drug delivery. Biomaterials 2015;65:43-55.

[27] Brglez V, Lambeau G, Petan T. Secreted phospholipases A2 in cancer: Diverse mechanisms of action. Biochimie 2014;107, Part A:114-23.

[28] Jones MR, Seeman NC, Mirkin CA. Programmable materials and the nature of the DNA 
bond. Science 2015;347.

[29] Pei H, Zuo X, Zhu D, Huang Q, Fan C. Functional DNA Nanostructures for Theranostic Applications. Acc Chem Res 2013;47:550-9.

[30] Sun W, Gu Z. Engineering DNA scaffolds for delivery of anticancer therapeutics. Biomater Sci 2015;3:1018-24.

[31] Tian C, Li X, Liu Z, Jiang W, Wang G, Mao C. Directed Self-Assembly of DNA Tiles into Complex Nanocages. Angew Chem Int Ed 2014;53:8041-4.

[32] Douglas SM, Marblestone AH, Teerapittayanon S, Vazquez A, Church GM, Shih WM. Rapid prototyping of 3D DNA-origami shapes with caDNAno. Nucleic Acids Res 2009;37:5001-6.

[33] Lee H, Lytton-Jean AKR, Chen Y, Love KT, Park AI, Karagiannis ED, et al. Molecularly self-assembled nucleic acid nanoparticles for targeted in vivo siRNA delivery. Nat Nanotechnol 2012;7:389-93.

[34] Sun W, Jiang T, Lu Y, Reiff M, Mo R, Gu Z. Cocoon-Like Self-Degradable DNA Nanoclew for Anticancer Drug Delivery. J Am Chem Soc 2014;136:14722-5.

[35] Hu R, Zhang X, Zhao Z, Zhu G, Chen T, Fu T, et al. DNA Nanoflowers for Multiplexed Cellular Imaging and Traceable Targeted Drug Delivery. Angew Chem Int Ed 2014;126:5931-6.

[36] Kim M-G, Park JY, Miao W, Lee J, Oh Y-K. Polyaptamer DNA nanothread-anchored, reduced graphene oxide nanosheets for targeted delivery. Biomaterials 2015;48:129-36.

[37] Kim M-G, Park JY, Shim G, Choi H-G, Oh Y-K. Biomimetic DNA nanoballs for oligonucleotide delivery. Biomaterials 2015;62:155-63. 
[38] Hong CA, Jang B, Jeong EH, Jeong H, Lee H. Self-assembled DNA nanostructures prepared by rolling circle amplification for the delivery of siRNA conjugates. Chem Commun 2014;50:13049-51.

[39] Roh YH, Lee JB, Shopsowitz KE, Dreaden EC, Morton SW, Poon Z, et al. Layer-by-Layer Assembled Anti-Sense DNA Microsponge Particles for Efficient Delivery of Cancer Therapeutics. ACS Nano 2014;8:9767-80.

[40] Lee JB, Hong J, Bonner DK, Poon Z, Hammond PT. Self-assembled RNA interference microsponges for efficient siRNA delivery. Nat Mater 2012;11:316-22.

[41] Ali MM, Li F, Zhang Z, Zhang K, Kang D-K, Ankrum JA, et al. Rolling circle amplification: a versatile tool for chemical biology, materials science and medicine. Chem Soc Rev 2014;43:3324-41.

[42] Lee JB, Peng S, Yang D, Roh YH, Funabashi H, Park N, et al. A mechanical metamaterial made from a DNA hydrogel. Nat Nanotechnol 2012;7:816-20.

[43] Qi H, Ghodousi M, Du Y, Grun C, Bae H, Yin P, et al. DNA-directed self-assembly of shape-controlled hydrogels. Nat Commun 2013;4:2275.

[44] Li J, Fan C, Pei H, Shi J, Huang Q. Smart Drug Delivery Nanocarriers with Self-Assembled DNA Nanostructures. Adv Mater 2013;25:4386-96.

[45] Brodin JD, Sprangers AJ, McMillan JR, Mirkin CA. DNA-Mediated Cellular Delivery of Functional Enzymes. J Am Chem Soc 2015;137:14838-41.

[46] Choi CHJ, Hao L, Narayan SP, Auyeung E, Mirkin CA. Mechanism for the endocytosis of 
spherical nucleic acid nanoparticle conjugates. Proc Natl Acad Sci USA 2013;110:7625-30.

[47] Sellner S, Kocabey S, Nekolla K, Krombach F, Liedl T, Rehberg M. DNA nanotubes as intracellular delivery vehicles in vivo. Biomaterials 2015;53:453-63.

[48] Yin H, Kanasty RL, Eltoukhy AA, Vegas AJ, Dorkin JR, Anderson DG. Non-viral vectors for gene-based therapy. Nat Rev Genet 2014;15:541-55.

[49] Jiang T, Mo R, Bellotti A, Zhou J, Gu Z. Gel-Liposome-Mediated Co-Delivery of Anticancer Membrane-Associated Proteins and Small-Molecule Drugs for Enhanced Therapeutic Efficacy. Adv Funct Mater 2013;24:2259-304.

[50] Shen W, Zhong H, Neff D, Norton ML. NTA Directed Protein Nanopatterning on DNA Origami Nanoconstructs. J Am Chem Soc 2009;131:6660-1.

[51] Jin Y, Yang F, Du L. Nanoassemblies containing a fluorouracil/zidovudine glyceryl prodrug with phospholipase A2-triggered drug release for cancer treatment. Colloids Surf B Biointerfaces $2013 ; 112: 421-8$.

[52] Kundu GC, Mukherjee AB. Evidence that porcine pancreatic phospholipase A2 via its high affinity receptor stimulates extracellular matrix invasion by normal and cancer cells. J Biol Chem $1997 ; 272: 2346-53$.

[53] Szoka F, Papahadjopoulos D. Procedure for preparation of liposomes with large internal aqueous space and high capture by reverse-phase evaporation. Proc Natl Acad Sci USA $1978 ; 75: 4194-8$.

[54] Aili D, Mager M, Roche D, Stevens MM. Hybrid Nanoparticle-Liposome Detection of 
Phospholipase Activity. Nano Lett 2010;11:1401-5.

[55] Jensen SS, Andresen TL, Davidsen J, Hoyrup P, Shnyder SD, Bibby MC, et al. Secretory phospholipase A2 as a tumor-specific trigger for targeted delivery of a novel class of liposomal prodrug anticancer etherlipids. Mol Cancer Ther 2004;3:1451-8.

[56] Zakaria AB, Picaud F, Rattier T, Pudlo M, Saviot L, Chassagnon R, et al. Nanovectorization of TRAIL with Single Wall Carbon Nanotubes Enhances Tumor Cell Killing. Nano Lett 2015;15:891-5.

[57] Lu Y, Hu Q, Lin Y, Pacardo DB, Wang C, Sun W, et al. Transformable liquid-metal nanomedicine. Nat Commun 2015;6:10066. 
a)

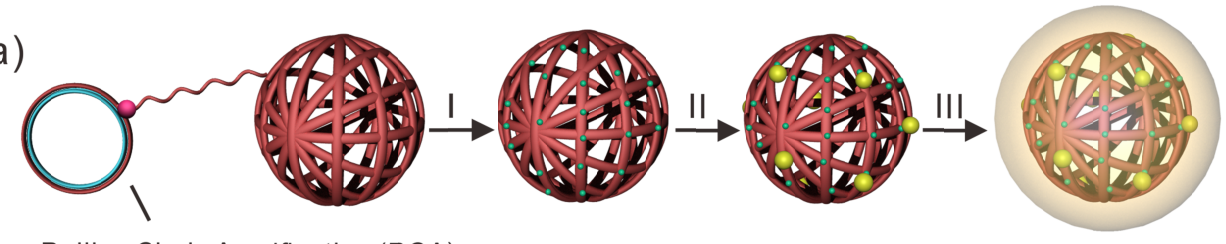

Rolling Circle Ampification (RCA)

b)
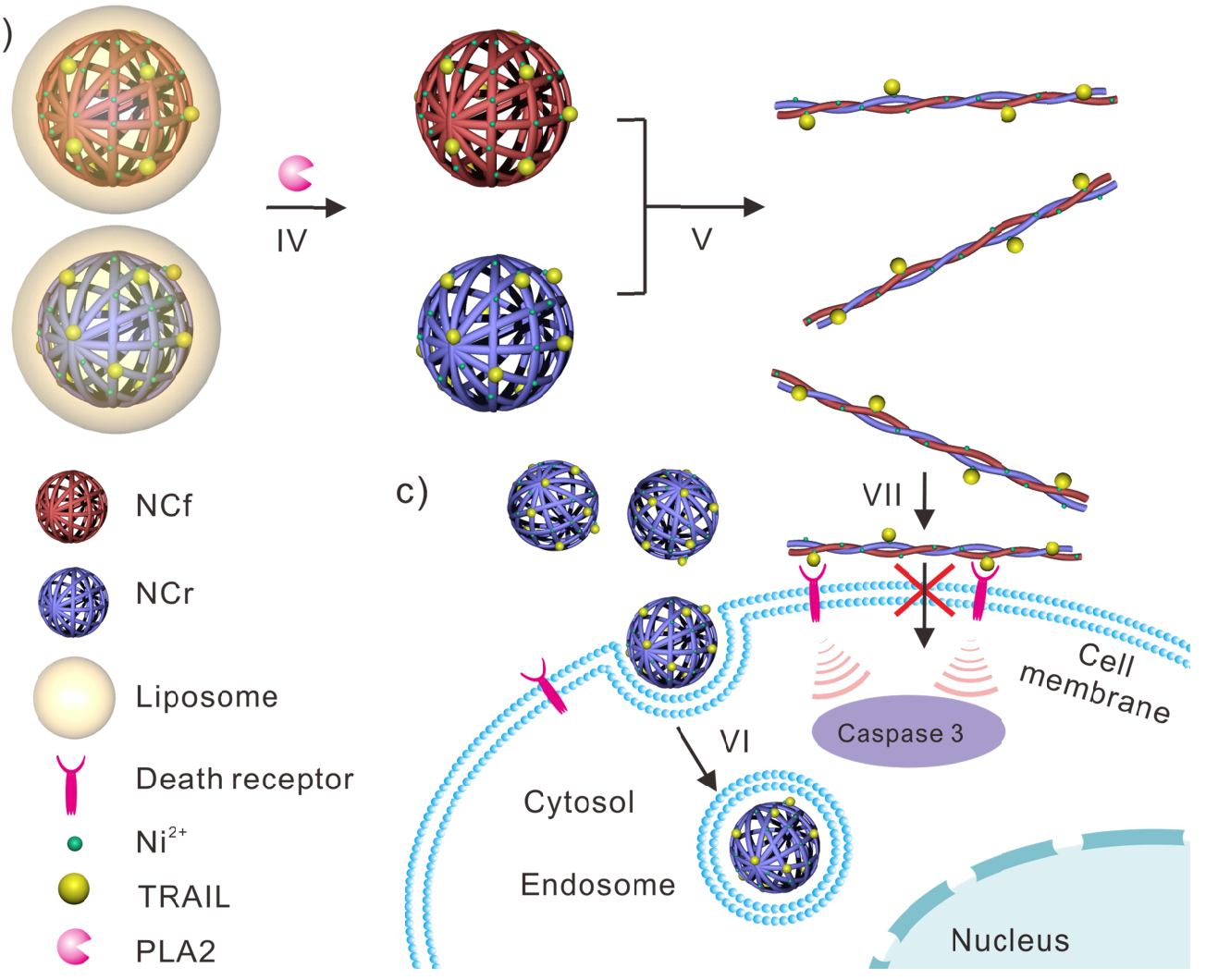

Fig. 1. Schematic of phospholipase activated membrane targeted cytokine delivery system. (a) Preparation of TRAIL-NC-L. The DNA NC was first prepared by RCA and then (I) modified with $\mathrm{Ni}^{2+}$. After (II) loading TRAIL through $\mathrm{Ni}^{2+}$-His tag affinity, (III) the TRAIL-NC was encapsulated into a POPC liposome that could be degraded by PLA2. (b) Main components of TRAIL-NC-L and mechanism of PLA2 triggered morphological transformation of the DNA NCs. (IV) Highly expressed PLA2 in the tumor microenvironment degrades the liposome shell to release TRAIL-NC. (V) Complementary DNA NCs hybridize into microscopic fibers. (c) Effect of the morphological change on TRAIL localization. (VI) TRAIL loaded spherical nanoparticle are efficiently internalized. (VII) Hybridized DNA fibers are highly impermeable to cell membrane, facilitaing the interaction of TRAIL and death receptors. 


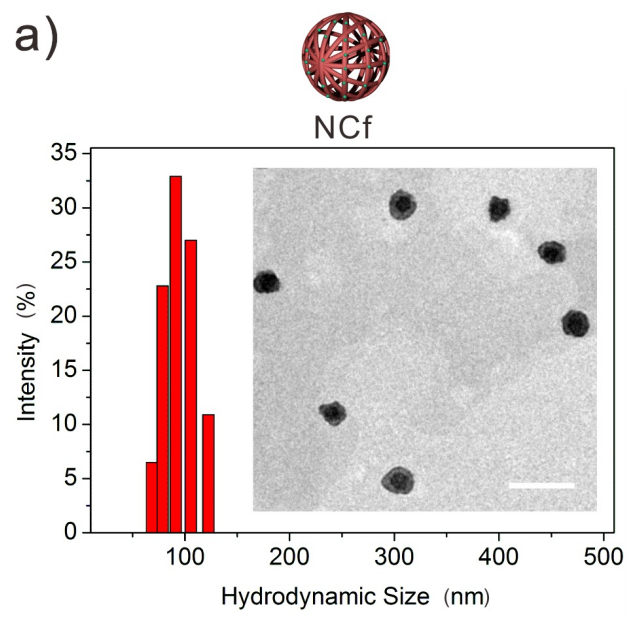

c)

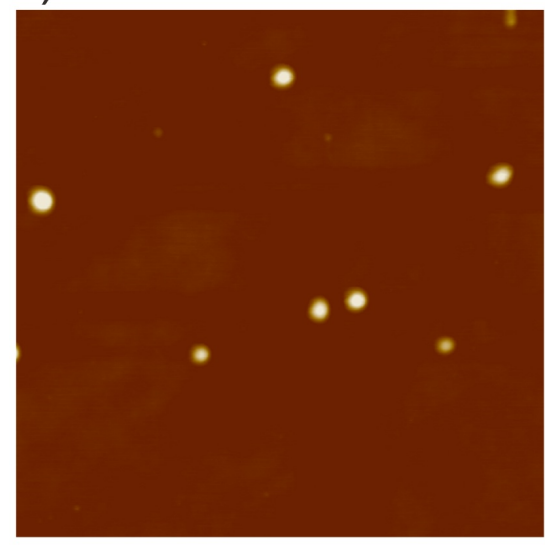

d)

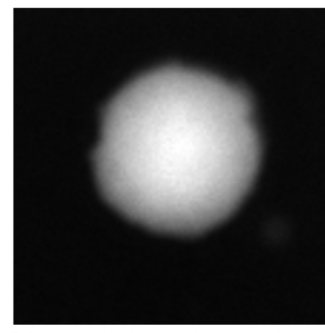

C
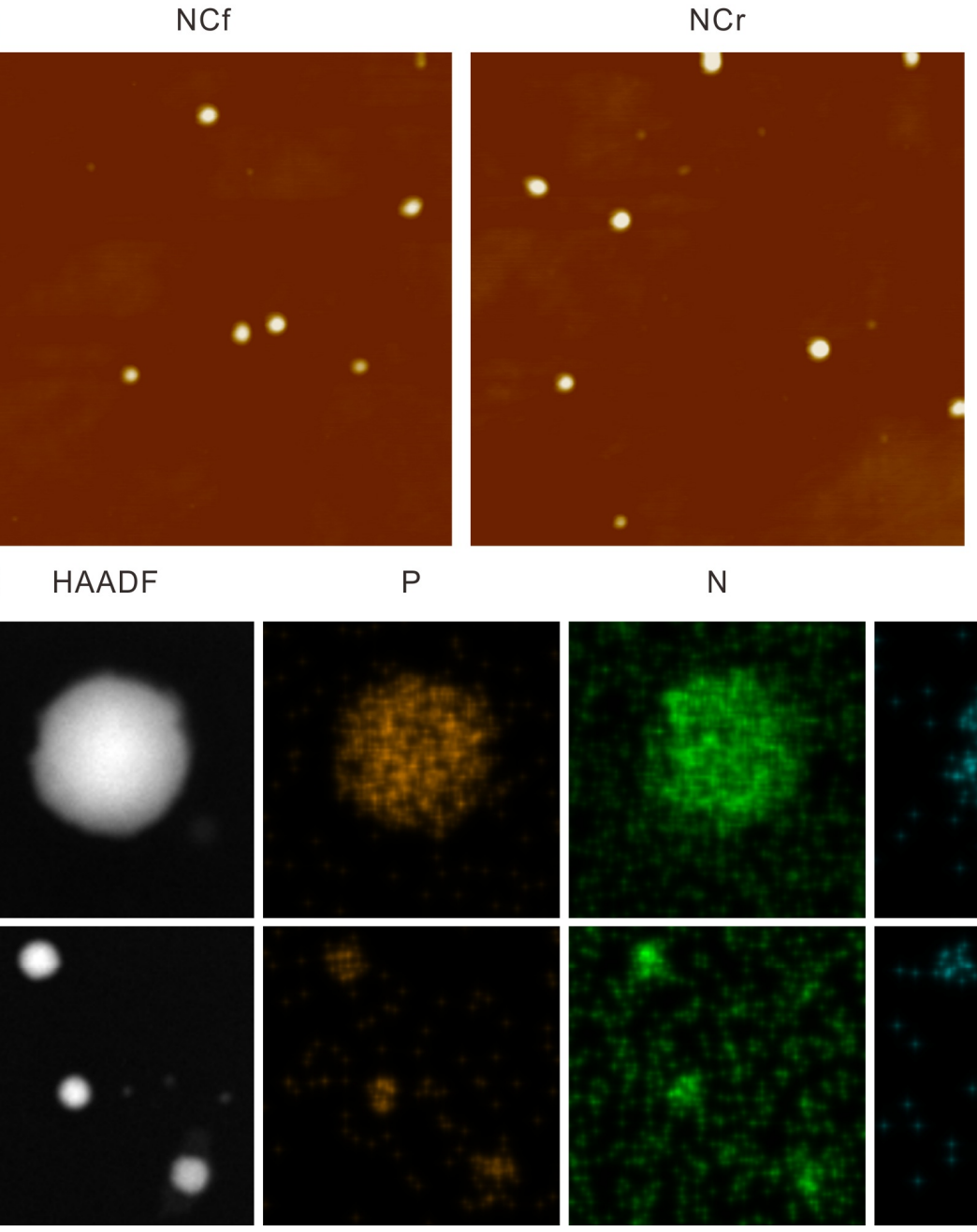

N
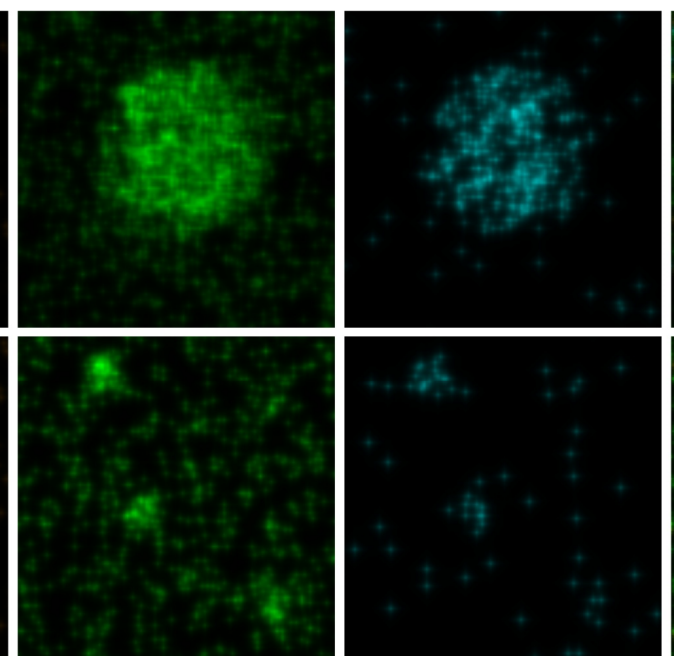

$\mathrm{Ni}$

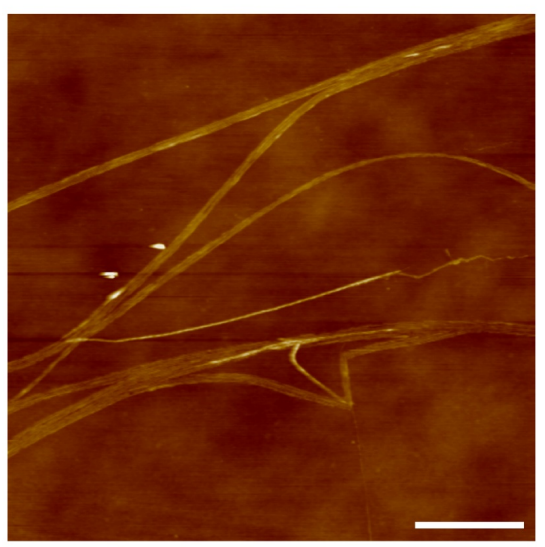

Merged

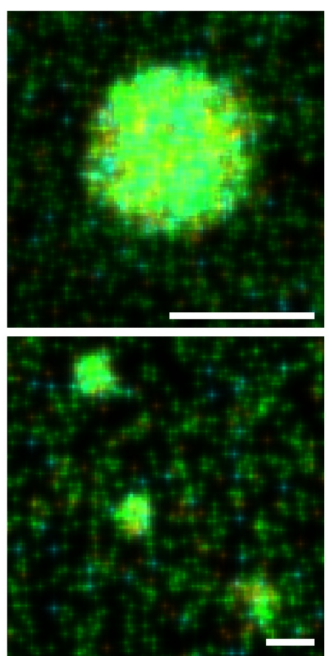

Fig. 2. (a) Hydrodynamic size distributions and TEM images of the synthesized DNA NCs. scale bars $200 \mathrm{~nm}$ (b) TEM image of NCf/NCr mix, scale bar $200 \mathrm{~nm}$. (c) AFM imaging of NCf, NCr, and NCf/NCr mix. Scale bar represents $500 \mathrm{~nm}$. (d) Representative element mapping of $\mathrm{Ni}^{2+}$ modified DNA NC. Shown here is $\mathrm{Ni}^{2+}$ modified NCf, scale bar represents $100 \mathrm{~nm}$. 
a)

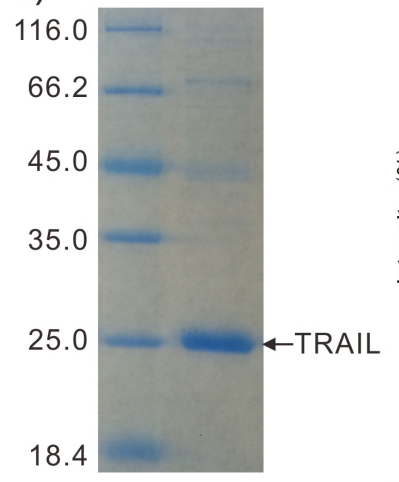

c)

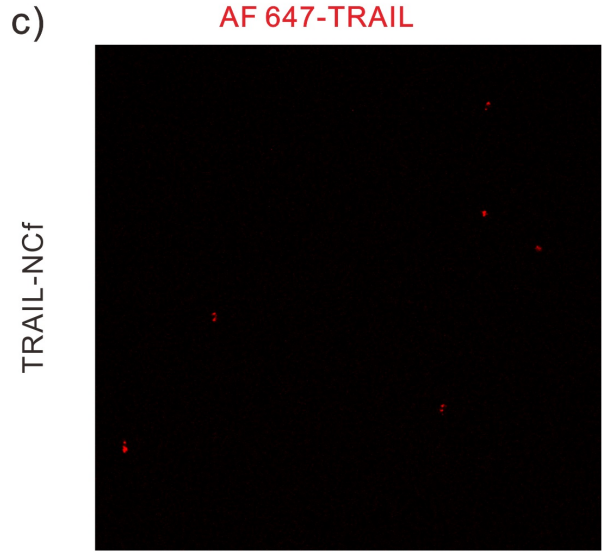

b)

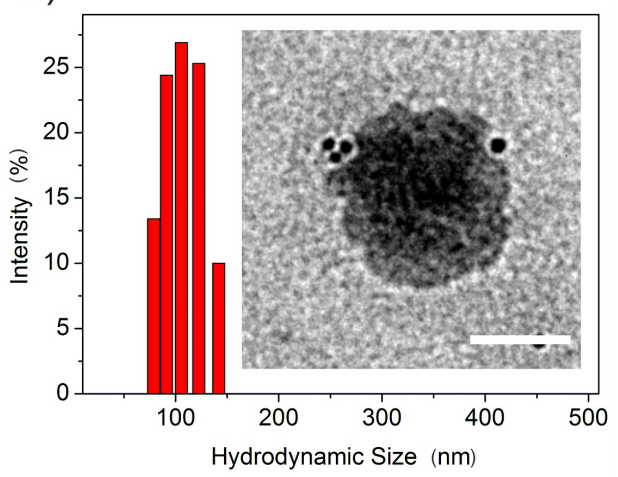

Hoechst

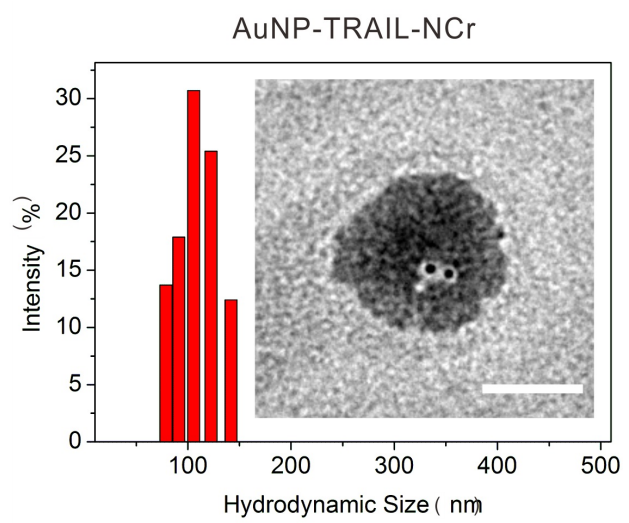

Merged
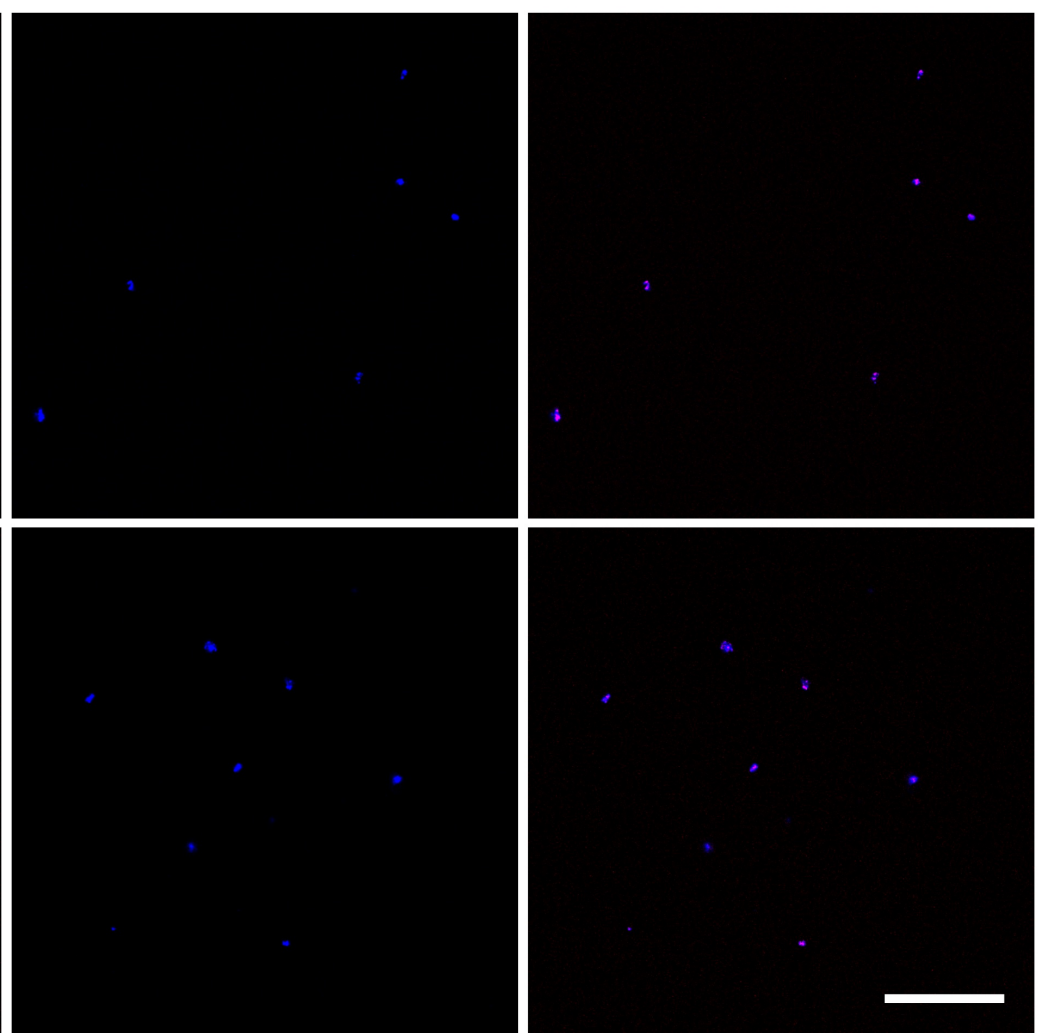

Fig. 3. (a) SDS-PAGE of purified TRAIL. (b) Hydrodynamic size distributions and TEM imaging of TRAIL loaded DNA NCs. TRAIL-NCf and TRAIL-NCr showed similar size distribution with a mean diameter of $\sim 104 \mathrm{~nm}$. TRAIL was stained with AuNP. Scale bars represent $100 \mathrm{~nm}$. (c) CLSM characterization of the colocalization of TRAIL and DNA in TRAIL-NCf and TRAIL-NCr. Red fluorescence indicated AF 647 labeled TRAIL; blue fluorescence showed Hoechst 33342 stained DNA NCs. Scale bar represents $10 \mu \mathrm{m}$. 

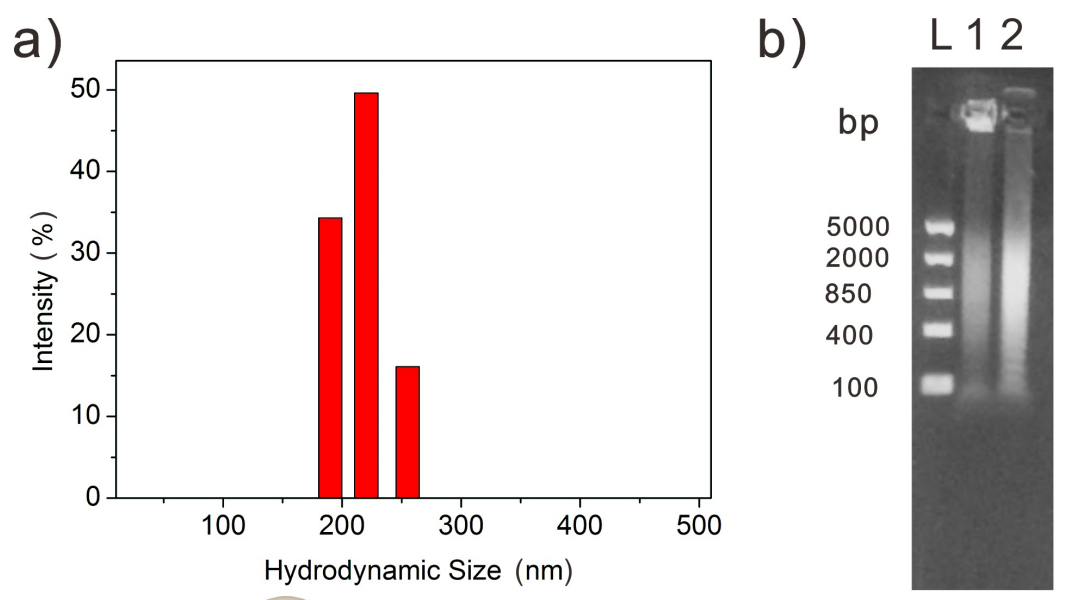

d)

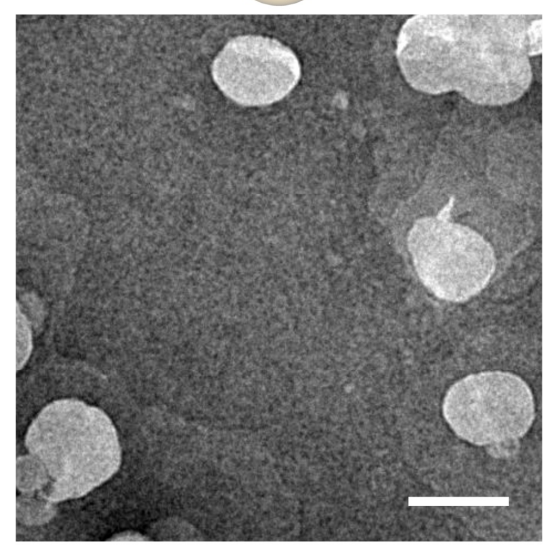

e)

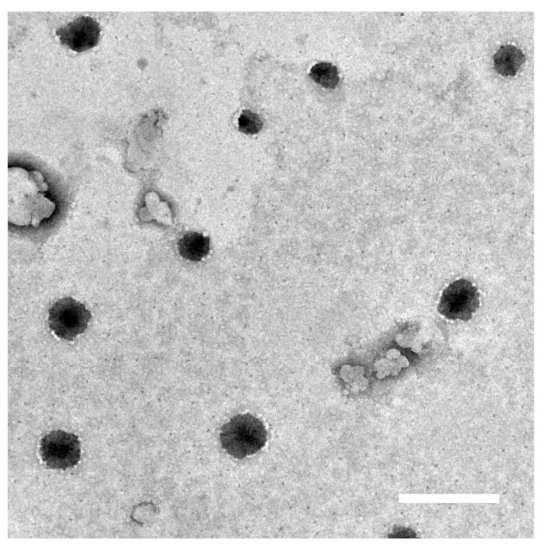

c)

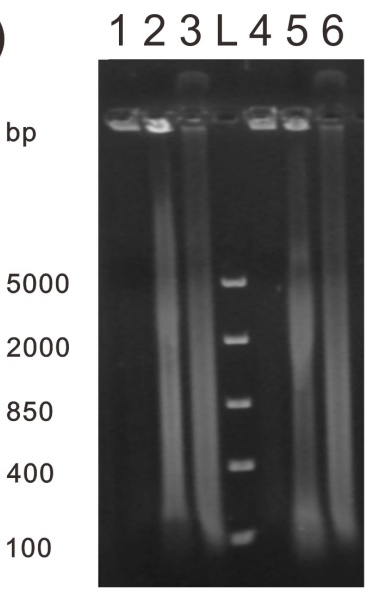

f)

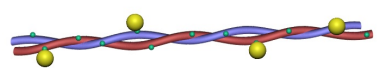

Fig. 4. (a) Hydrodynamic size distribution of POPC liposome encapsulating TRAIL-NCf. (b) Agarose gel electrophoresis analysis of encapsulating DNA NC into POPC liposome. Lane L showed DNA ladder, Lane 1: Unpurified TRIAL-NCf-L, Lane 2: Unpurified TRIAL-NCf-L treated with $1 \%$ Triton X-100. Encapsulation efficiency was estimated from the band intensity by Image $\mathrm{J}$, where the encapsulated amount is the difference between Lane 2 and Lane 1. (c) Release of TRAIL-NC from POPC liposome. Lane L showed DNA ladder; Lane 1 and 4, purified POPC liposome encapsulating TRAIL-NCf and TRAIL-NCr; Lane 2 and 5, TRAIL-NCf-L and TRAIL-NCr-L treated with PLA2; Lane 3 and 6, TRAIL-NCf-L and TRAIL-NCr-L treated with $1 \%$ Triton X-100 as $100 \%$ release. (d) Representative TEM image of POPC liposome encapsulating TRAIL-NC. Shown is TRAIL-NCf-L. (e) TEM image of TRAIL-NCf-L after PLA2 treatment. (f) TEM image of TRAIL-NCf-L/TRAIL-NCr-L after PLA2 treatment. Scale bars all indicate $200 \mathrm{~nm}$. 


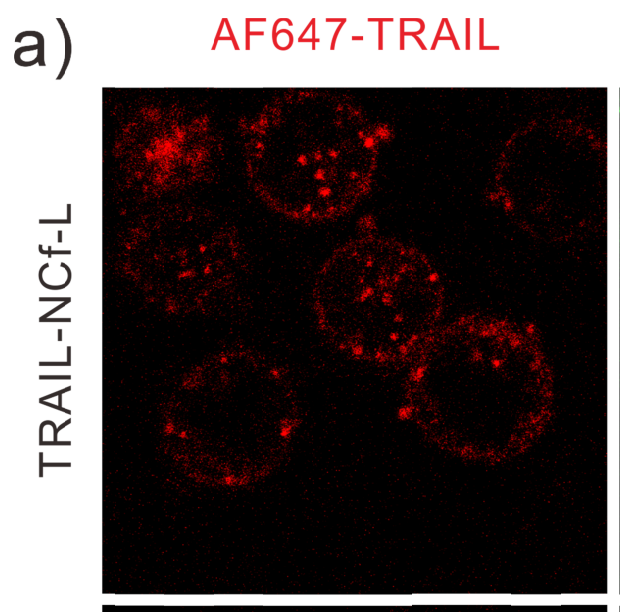

AF488-WGA

Merged
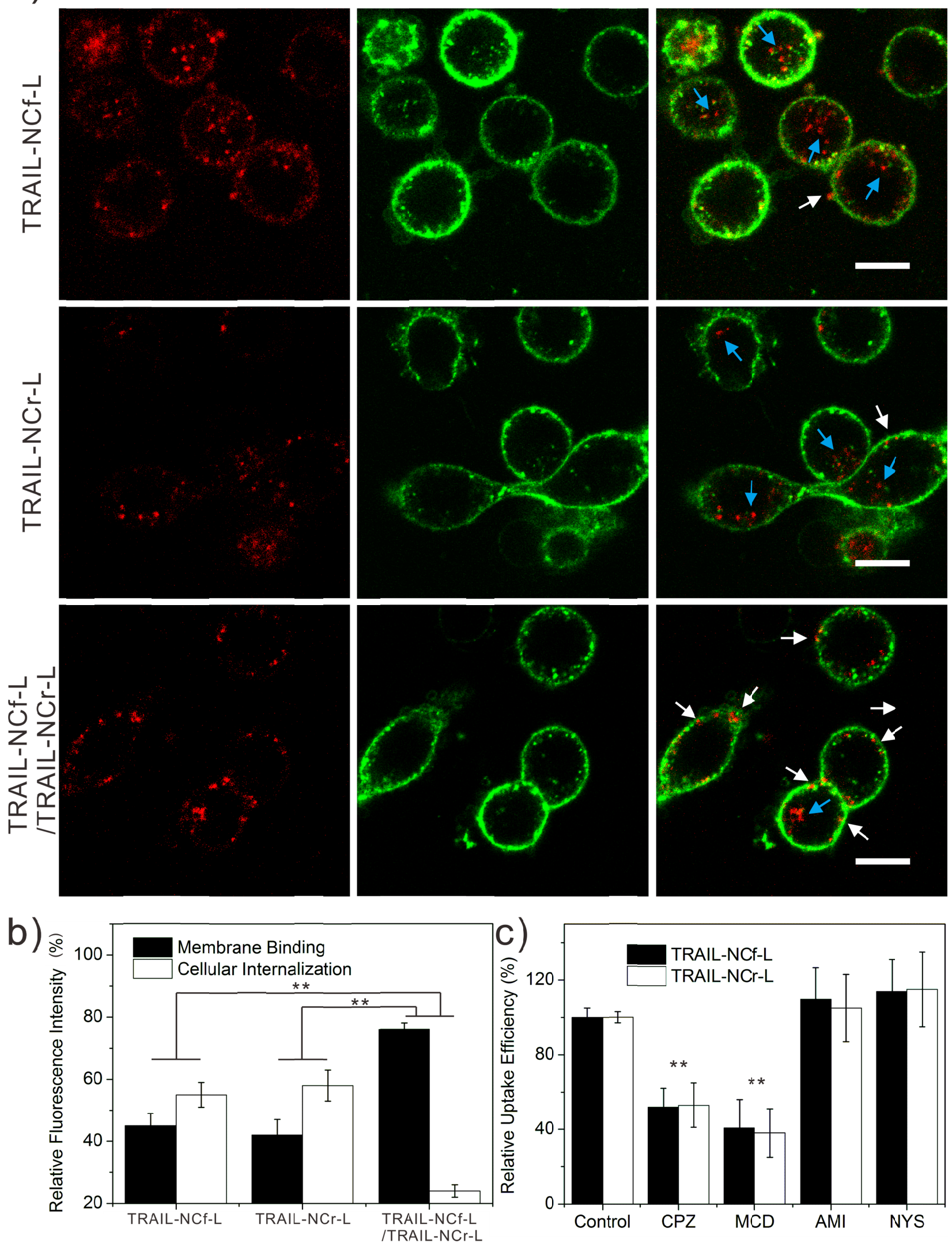
Fig. 5. (a) CLSM analysis of subcellular localization of delivered TRAIL. COLO 205 cells were incubated with TRAIL-NCf-L and TRAIL-NCr-L separately or simultaneously after PLA2 pretreatment. TRAIL was labeled with AF 647 and membrane of COLO 205 cells was stained with AF488-WGA. White arrows indicate TRAIL on cell membrane and blue arrows indicate internalized TRAIL. Scale bars indicate $20 \mu \mathrm{m}$. (b) Quantitative analysis of the amount of TRAIL internalized by COLO 205 cells or bound on cell membrane. (c) Endocytosis pathway analysis of TRAIL delivered by TRAIL-NCf-L and TRAIL-NCr-L. Data was presented as mean \pm SD ( $\mathrm{n}=$ 3). $* * P<0.01$. 
a)

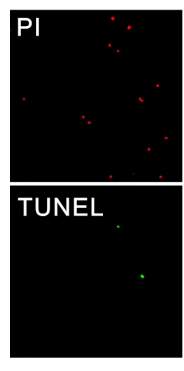

TRAIL-NCf-L

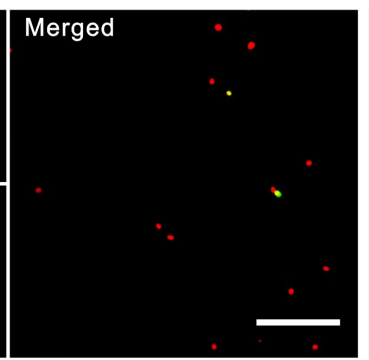

TRAIL-NCr-L

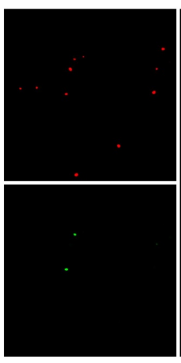

TRAIL-NCf-L

ITRAIL-NCr-L

b)
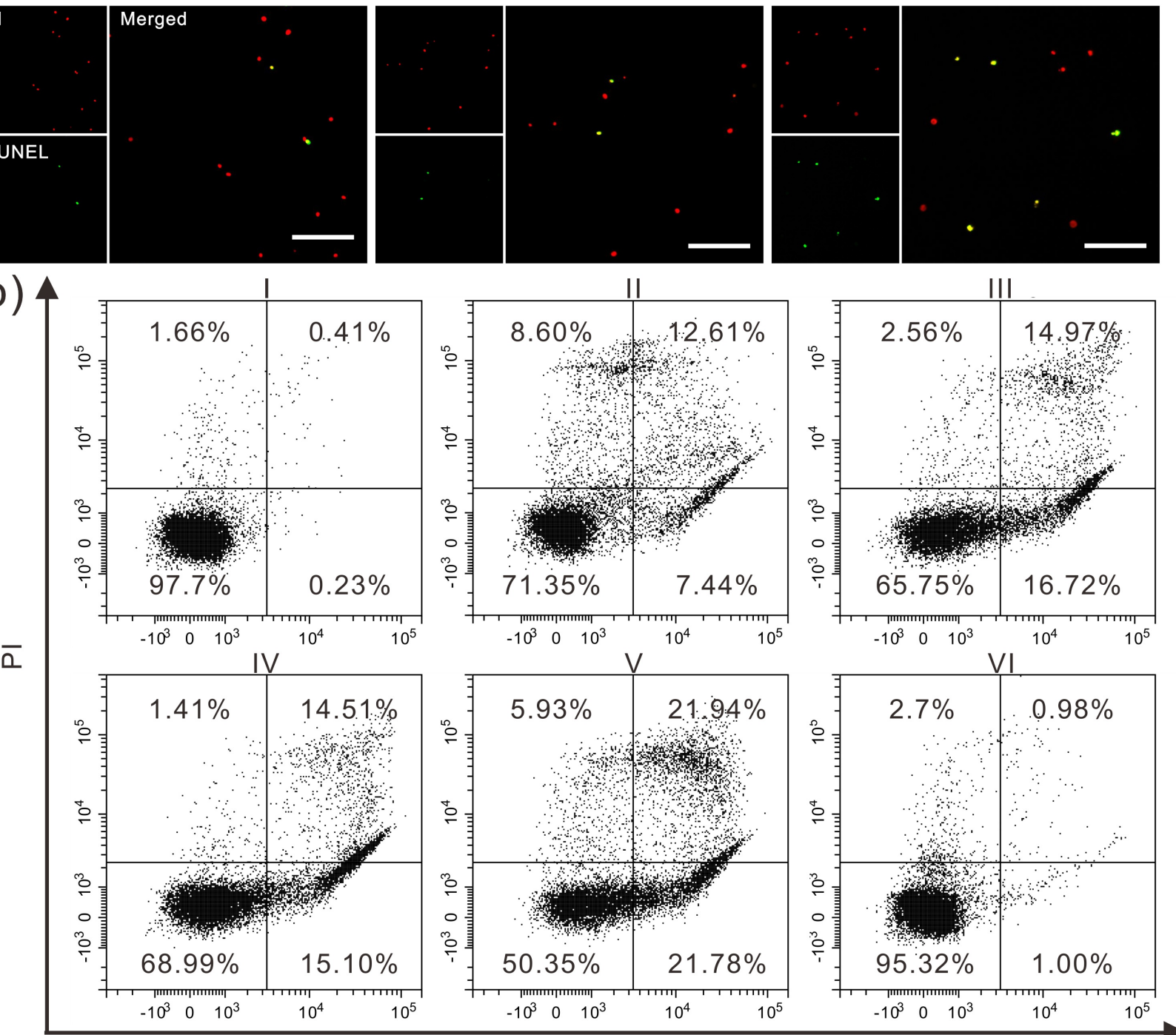

Annexin-FITC
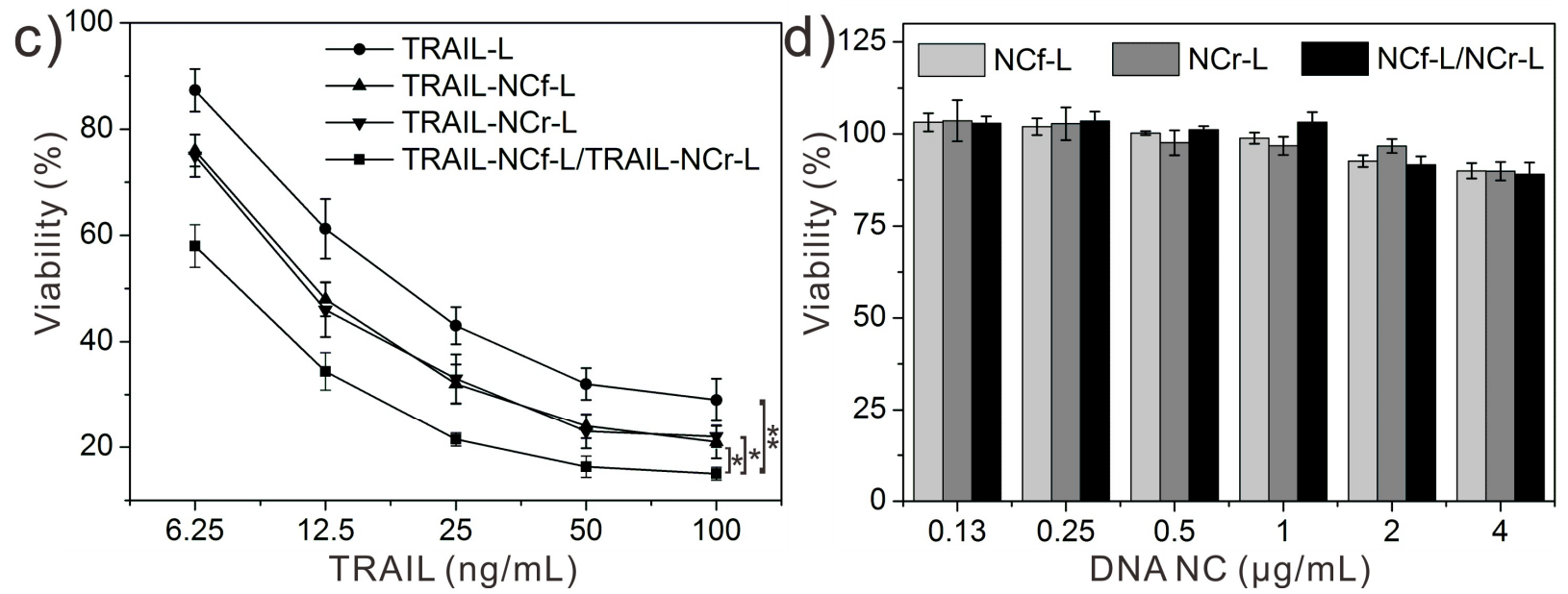

Fig. 6. (a) APO-BrdU TUNEL assay of COLO 205 apoptosis induced by different TRAIL delivery formulations after PLA2 pretreatment. Scale bar indicates $200 \mu \mathrm{m}$. (b) Annexin 
V-FITC/PI staining based flow cytometry analysis of COLO 205 apoptosis after treating with different TRAIL delivery formulations for $12 \mathrm{~h}$. I, control cell untreated with any formulation; II, TRAIL-L after PLA2 pretreatment; III, TRAIL-NCf-L after PLA2 pretreatment; IV, TRAIL-NCr-L after PLA2 pretreatment; V, TRAIL-NCf-L/TRAIL-NCr-L after PLA2 pretreatment; VI, TRAIL-NCf-L/TRAIL-NCr-L without PLA2 pretreatment. (c) In vitro cytotoxicity of TRAIL-L, TRAIL-NCf-L, TRAIL-NCr-L and TRAIL-NCf-L/TRAIL-NCr-L after PLA2 pretreatment. Colo 205 cells were treated with different formulations for $24 \mathrm{~h}$. (d) In vitro cytotoxicity of carriers without loaded TRAIL after PLA2 pretreatment. Data were presented as mean $\pm \mathrm{SD}(\mathrm{n}=6) . * P<0.05, * * P<0.01$. 
Table 1 Sequences of DNA oligos

\begin{tabular}{lll}
\hline & Nanocarriers & Sequences \\
\hline RCA & NCf & 5'phos-ACAGGCCAACCCCCCATGACAACGTGGGACAGACGCAACCTC \\
templates $^{\mathbf{a}}$ & & TGTAGTGAAAAAACATTACGCGTAATGAAAAAAT 3' \\
& $\mathrm{NCr}$ & 5'phos-ATTTTTTCATTACGCGTAATGTTTTTCACTACAGAGGTTGCGTC \\
& & TGTCCCACGTTGTCATGGGGGGTTGGCCTGT 3' \\
Primers & $\mathrm{NCf}$ & 5' CACTACAGAGG 3' \\
& $\mathrm{NCr}$ & 5' CCTCTGTAGTG 3' \\
\hline
\end{tabular}

${ }^{\mathrm{a}}$ Palindromic sequence underlined for particle assembly. 